\title{
Choledochoduodenal fistula caused by cholangio- carcinoma of the distal common bile duct
}

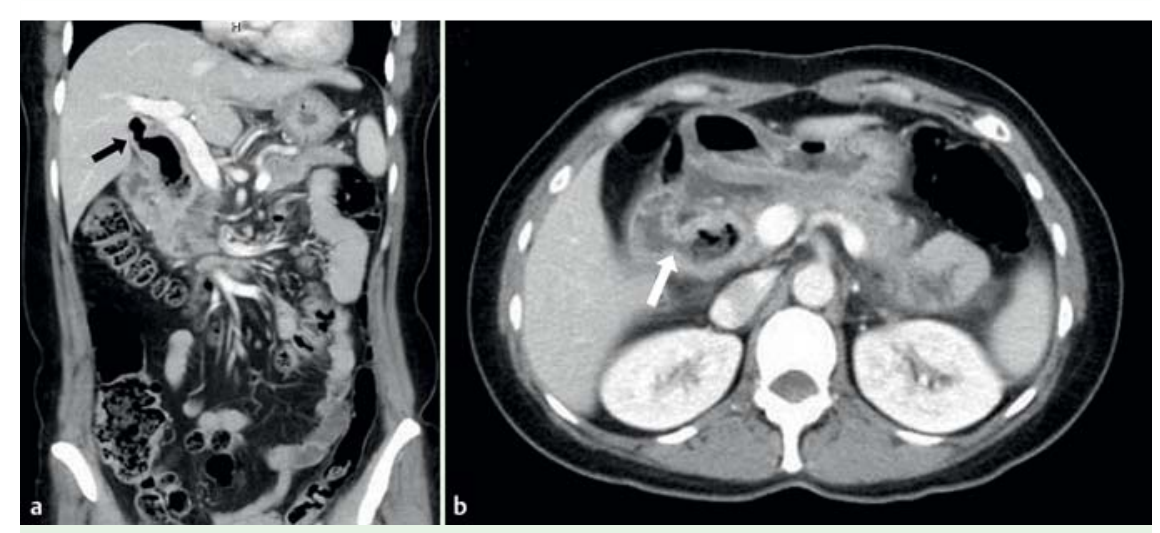

Fig. 1 Computed tomography (CT) of the abdomen showed (a) pneumobilia (black arrow) in both the common hepatic duct and the common bile duct (CBD) and (b) a possible choledochoduodenal fistula (white arrow).
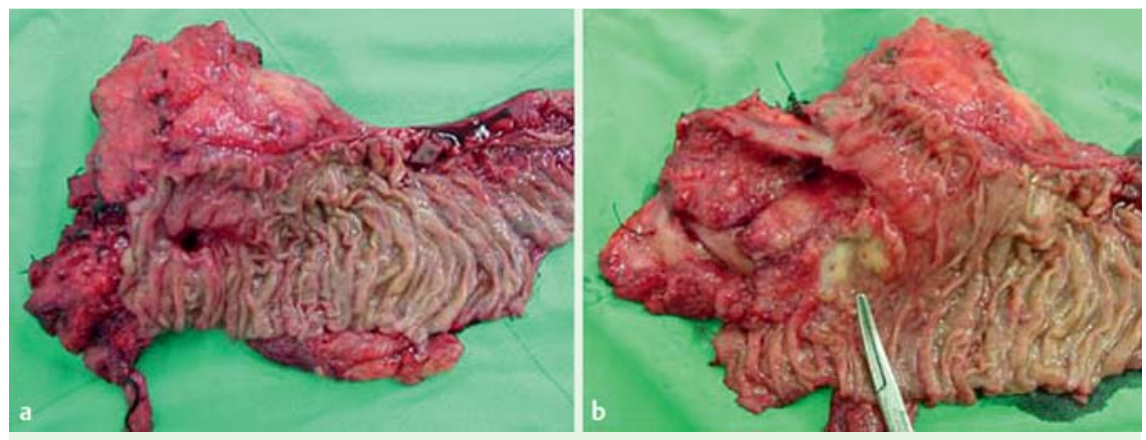

Fig. 3 a Compatible with the endoscopic findings, the surgical specimen showed the orifices of the fistula and the papilla of Vater. $\mathbf{b}$ A papillary tumor was found in the distal CBD, obstructing the duct.

Biliary-enteric fistula is a relatively rare condition involving a communication between the biliary tree and the gastrointestinal tract [1,2]. Parapapillary choledochoduodenal fistula is usually asymptomatic and therefore this disorder has usually been diagnosed incidentally [3]. We report a rare case of choledochoduodenal fistula caused by adenocarcinoma of the distal common bile duct (CBD), which was suspected on computed tomography (CT) of the abdomen and confirmed by esophagogastroduodenoscopy (EGD).

A 48-year-old woman presented to the emergency department with a 1-day history of epigastric pain. For the previous 2 months she had suffered intermittent epigastric pain with radiation to the back. She had no history of gallstone or gastroduodenal ulcer. She was afebrile on admission, and physical examination demonstrated epigastric tenderness. Laboratory data showed a white blood cell count of $8400 / \mu \mathrm{L}$, an alkaline phosphatase level of $77 \mathrm{U} / \mathrm{L}$, and normal levels of tumor markers such as carcinoembryonic antigen and cancer antigen 19-9. CT of the abdomen showed pneumobilia in both the common hepatic duct and the CBD ( Fig. 1a) and a probable choledochoduodenal fistula ( $\bullet$ Fig. 1b). EGD revealed the orifice of a choledochoduodenal fistula $3.0 \mathrm{~cm}$ proximal to the papilla of Vater ( $\bullet$ Fig. 2) and a tumor in the distal CBD. Biopsy was performed and pathological examination showed moderately differentiated adenocarcinoma of the CBD. On the basis of these images, the patient was diagnosed as having advanced cholangiocarcinoma associated with a parapapillary choledochoduodenal fistula. She underwent pylorus-preserving pancreaticoduodenectomy. Compatible with the endoscopic findings, the surgical specimen showed the orifices of the fistula and the papilla of Vater ( $\bullet$ Fig. $3 a$ ).

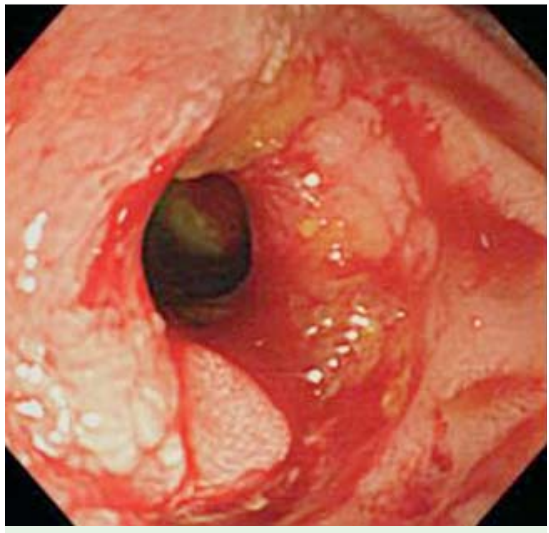

Fig. 2 Upper gastrointestinal panendoscopy revealed the orifice of a choledochoduodenal fistula.

A papillary tumor was found in the distal $\mathrm{CBD}$, where it was causing obstruction of the CBD ( Fig. 3b). Pathological examination showed cholangiocarcinoma of the $\mathrm{CBD}$, American Joint Committee on Cancer stage T4NOMO (stage III). The postoperative course was uneventful.

A choledochoduodenal fistula is an abnormal passage between the CBD and the duodenum. Common etiologies include instrumentation (iatrogenic), choledocholithiasis, and duodenal ulcer. Choledochoduodenal fistulas associated with cancers are extremely rare, with nine cases reported in the literature; the cancers involved included ampullary cancer, duodenal cancer, gallbladder cancer, pancreatic cancer, and cholangiocarcinoma [2,4-8]. These patients presented with epigastralgia and anorexia. CT of the abdomen often showed pneumobilia. EGD or endoscopic retrograde cholangiopancreatography (ERCP) is employed to diagnose choledochoduodenal fistulas, and associated cancers are confirmed by biopsy.

In rare cases, the fistula is a complication secondary to an occult malignancy such as biliary adenocarcinoma. For clinical evaluation of choledochoduodenal fistula of unknown etiology, and if occult malignancy is suspected, EGD or ERCP should be performed. The case we have reported of a patient with adenocarcinoma of the CBD causing a choledochoduodenal fistula highlights the importance of endoscopy to diagnose choledochoduodenal fistula and occult carcinoma of the biliary tract. 


\section{Endoscopy_UCTN_Code_CCL_1AZ_2AC}

\section{C.-T. Lin ${ }^{1 *}$, K.-F. Hsu ${ }^{1 *}$, J.-C. Yu ${ }^{1}$, H.-C. Chu' ${ }^{2}$, C.-B. Hsieh ${ }^{1}$, C.-Y. Fu', Z.-J. Hong', D.-C. Chan ${ }^{1}$}

1 Division of General Surgery, Department of Surgery, Tri-Service General Hospital, National Defense Medical Center, Taipei, Taiwan, Republic of China

2 Division of Hepatogastroenterology, Department of Medicine, Tri-Service General Hospital, National Defense Medical Center, Taipei, Taiwan, Republic of China

\footnotetext{
* C. T. Lin and K. F. Hsu contributed equally to this work as first author.
}

\section{References}

1 Jorge A, Diaz M, Lorenzo J et al. Choledochoduodenal fistulas. Endoscopy 1991; 23: 76 78

2 Kuroki T, Fukuda K, Tajima Yet al. Parapapillary choledochoduodenal fistula associated with cholangiocarcinoma. J Hepatobiliary Pancreat Surg 2005; 12: 143-146

3 Tanaka M, Ikeda S. Parapapillary choledochoduodenal fistula: an analysis of 83 consecutive patients diagnosed at ERCP. Gastrointest Endosc 1983; 29: 89-93

4 Chen SY, Lin CH, Yu JC et al. Adenosquamous carcinoma of the common bile duct with choledochoduodenal fistula. Chir Gastroenterol 2006; 22: 88-91

5 Ji JS, Kim HK, Kim SS et al. Periampullary choledochoduodenal fistula associated with ampulla of Vater carcinoma. Dig Dis Sci 2007; 52: $1592-1593$

6 Okabe T, Ohwada S, Ogawa T et al. Gallbladder carcinoma with choledochoduodenal fistula: a case report with surgical treatment. Hepatogastroenterology 1999; 46: $1660-1663$
7 Imaeda K, Katagiri K, Ando T et al. Multiple parapapillary choledochoduodenal fistulas with ampullary carcinoma. Hepatogastroenterology 1998; 45: 2097-2100

8 Tsai CJ. Primary adenocarcinoma of the duodenum with choledochoduodenal fistula. Scand J Gastroenterol 1994; 29: 930-933

\section{Bibliography}

DOI $10.1055 / \mathrm{s}-0029-1215325$

Endoscopy 2009; 41: E319-E320

(c) Georg Thieme Verlag KG Stuttgart · New York . ISSN 0013-726X

\section{Corresponding author}

\section{D.-C. Chan, MD}

Division of General Surgery

Department of Surgery

Tri-Service General Hospital

No. 325, Cheng-Kung Road

Sec 2, Neihu 114

Taipei

Taiwan

Fax: +886-2-87927372

chris790826@yahoo.com.tw 